Article

\title{
An Advanced Characterization Method for the Elastic Modulus of Nanoscale Thin-Films Using a High-Frequency Micromechanical Resonator
}

\author{
Yun Young Kim \\ Division of Mechanical, Automotive, and Robot Component Engineering, Dong-eui University, \\ Busan 47340, Korea; ykim@deu.ac.kr; Tel.: +82-51-890-1649
}

Received: 30 May 2017; Accepted: 12 July 2017; Published: 15 July 2017

\begin{abstract}
Nanoscale materials have properties that frequently differ from those of their bulk form due to the scale effect, and therefore a measurement technique that can take account of such material characteristics with high accuracy and sensitivity is required. In the present study, advanced nanomechanical metrology was developed for evaluation of elastic properties of thin-film materials. A $52 \mathrm{~nm}$ thick chromium ( $\mathrm{Cr}$ ) film was deposited on a high-speed micromechanical resonator using an e-beam evaporator, and the structure was excited to resonate using an ultrasonic platform. The resonant frequencies for the first and second flexural vibration modes were measured using laser interferometry, and they were compared to analytical estimation from the classical beam theory. Results show that the experimental data are in excellent agreement with the theory, within $1 \%$ of the relative error, and a mass sensitivity up to $10.5 \mathrm{~Hz} / \mathrm{fg}$ was achieved. Thus, the scale effect that reduced the Young's modulus of $\mathrm{Cr}$ by $49.8 \%$ compared to its bulk property was correctly recognized by the proposed method.
\end{abstract}

Keywords: micromechanical resonator; materials characterization; thin-film; elastic modulus

\section{Introduction}

Mechanical properties of nanoscale thin-films have drawn significant attention in the fields of science and engineering, not only for intellectual reasons but for practical applications in microelectromechanical systems (MEMS) and semiconductor devices. For example, the state-of-the-art three-dimensional memory devices require micro/nanomechanical stability design and simulation in order to prevent structural failures during the microfabrication process, unlike their predecessors based on planar device technologies [1]. During the design, however, properties of bulk materials cannot be used because they frequently deviate from literature values due to the scale effect and also vary depending on process conditions. Therefore, it is essential to develop an evaluation technique that accounts for such material characteristics.

Among many techniques such as acoustic microscopy [2], nanoindentation testing [3], microtensile testing [4], laser ultrasonics [5], and so on, micromechanical resonator-based sensing provides an effective and convenient way to study characteristics of thin-films and nanoscale materials [6]. In the microresonator testing, attachment of molecules onto the surface of a cantilever beam-like MEMS structure results in a shift of its resonant frequency. Therefore, properties of the attached materials can be calculated once the frequency shift is measured and theoretically analyzed. To improve the microresonator's performance, the following measures have been taken: increasing the operating frequency by using higher order resonance modes and decreasing the resonator mass by reducing 
the volume of the structure, due to the mass sensitivity $(S)$ of the microresonator being equal to the resonant frequency shift $(\Delta f)$ divided by the mass addition $(\Delta m)$ [7]:

$$
S=\Delta f / \Delta m
$$

Reducing the volume of the structure, however, addresses problems in microfabrication and instrumentation [8]. For example, a position sensitive detector (PSD)-equipped atomic force microscopy (AFM)-based approach is conventionally used for the evaluation, but its sensitivity is limited by instrumentation issues arising from the minimum angle of beam deflection or, in turn, the minimum length of the micromechanical resonator, since it depends on the optical lever method for detection. Increasing the resonant frequency is also limited by the bandwidth of PSD. Although certain approaches have been demonstrated to increase the operation frequency to the megahertz $(\mathrm{MHz})$ and gigahertz range [9-12], a typical AFM probe still resonates in the lower kilohertz frequency range. Therefore, faster actuation and sensing are required to enhance the resolution.

Here, an advanced nanomaterials characterization method is introduced using a micromechanical resonator actuating in the $\mathrm{MHz}$ frequency range. The resonant frequency shift of the resonator upon deposition of a nanoscale thin-film, which is a chromium (Cr) layer for demonstration in this study, is detected so that the film's elastic modulus can be evaluated. The time-domain waveform of the resonance signal is measured using a path-stabilized Michelson interferometer-instead of using the optical lever method-for the high frequency detection, and the vibration mode of the micromechanical resonator is identified using the Euler-Bernoulli beam theory. The advantage of the proposed technique is that increasing the actuation and detection frequencies to the $\mathrm{MHz}$ range makes it possible to evaluate nanomaterials with high sensitivity and accuracy.

\section{Materials and Methods}

\subsection{Materials}

A high-speed micromechanical resonator (SD-USC-F1.2-k7.3-TL, Nanoworld AG, Neuchâtel, Switzerland) was used in this study, as shown in Figure 1. The length $(L)$ and width $(b)$ of the structure are $20 \mu \mathrm{m}$ and $10 \mu \mathrm{m}$, respectively. It has $30 \mathrm{~nm}$ thick gold $(\mathrm{Au})$ layers on the top and bottom sides of the $670 \mathrm{~nm}$ thick quartz core, for optical reflection of a detection laser beam.

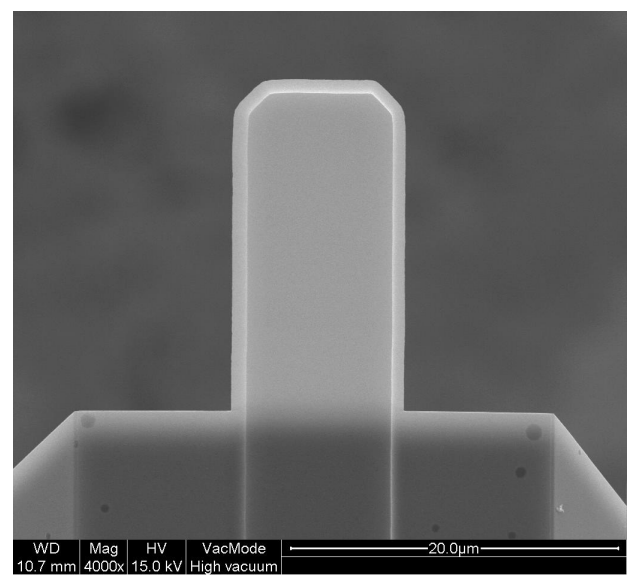

(a)

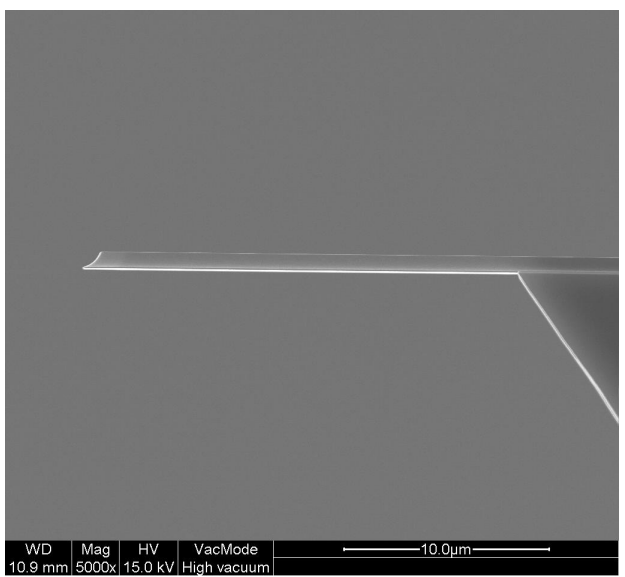

(b)

Figure 1. Field emission scanning electron microscopy pictures of the micromechanical resonator: (a) top-view; (b) side-view.

A $52 \mathrm{~nm}$ thick $\mathrm{Cr}$ layer was additionally deposited on the top surface using an e-beam evaporator (FC-2000, Temescal Systems, Livermore, CA, USA). The chamber pressure and deposition rate were 
maintained at $1.1 \times 10^{-7}$ Torr and $2.0 \AA / \mathrm{s}$, respectively, during the process. The film thickness was checked using a profilometer (P6, KLA Tencor, Milpitas, CA, USA) after the deposition was complete-since the film thickness is an important parameter that influences the Young's modulus of Cr film in this experiment, a bare silicon (Si) (100) wafer with a polished surface was also installed in the chamber and partially covered to measure the thickness of the $\mathrm{Cr}$ layer. The measurement data in Figure 2 show that the film thickness is approximately $52 \pm 2 \mathrm{~nm}$.

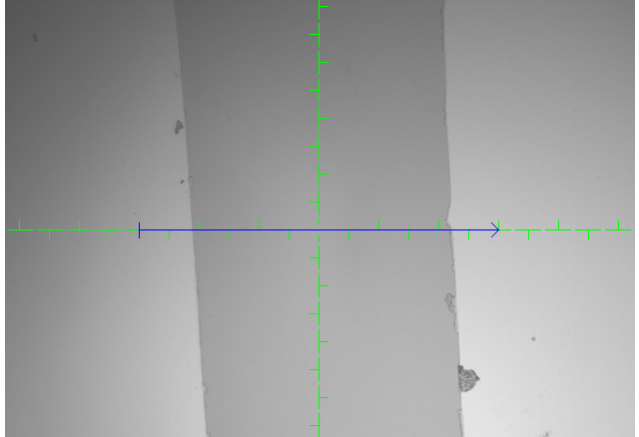

(a)

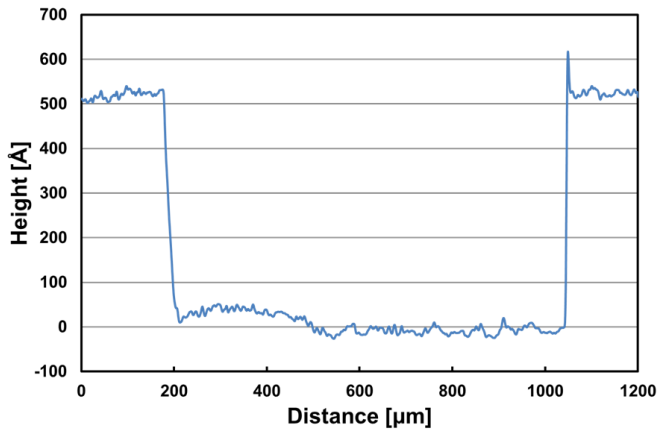

(b)

Figure 2. (a) A microscopy image of the chromium-coated silicon wafer. The dark area in the center was partially covered during the film deposition for the thickness measurement along the blue arrow; (b) thickness measurement data using a profilometer.

To study microstructures of the film, the surface morphology was imaged using an atomic force microscopy (AFM L-trace II, Hitachi High-Tech Science Corporation, Tokyo, Japan) operating in a tapping mode. $512 \times 512$ pixels were measured within an area of $1 \times 1 \mu \mathrm{m}^{2}$ at a scanning speed of $1 \mathrm{~Hz}$. In addition, grazing incidence $X$-ray diffraction (GIXRD) patterns were measured (X'pert Pro, PANalytical B.V., Almelo, Netherlands) in the range of $30^{\circ}-90^{\circ}$ with an angular step of 0.02 at a scan step time of $1 \mathrm{~s}$. Due to the difficulty of directly measuring the chromium film on the microresonator surface with an area of only $20 \times 10 \mu \mathrm{m}^{2}$, the reference sample (the same film on a 4 inch Si(100) wafer) was measured instead. The AFM image introduced in Figure 3a reveals that the surface roughness $\left(R_{a}\right)$ is $0.79 \mathrm{~nm}$. Figure $3 \mathrm{~b}$ shows that the GIXRD patterns and peaks are located at $2 \theta=44^{\circ}, 65^{\circ}$, and $82^{\circ}$, corresponding to the $\operatorname{Cr}(110), \operatorname{Cr}(200)$, and $\operatorname{Cr}(211)$ planes, respectively, according to the Inorganic Crystal Structure Database (ICSD), reference code No. 98-062-5717. The stick patterns for silicon (ICSD reference code No. 98-005-1688) was also plotted together in Figure 3b.

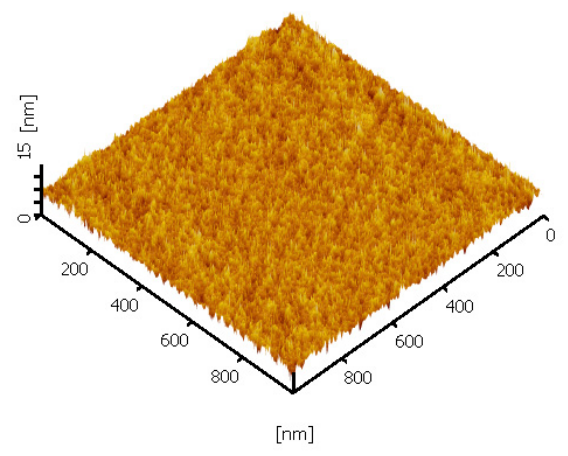

(a)

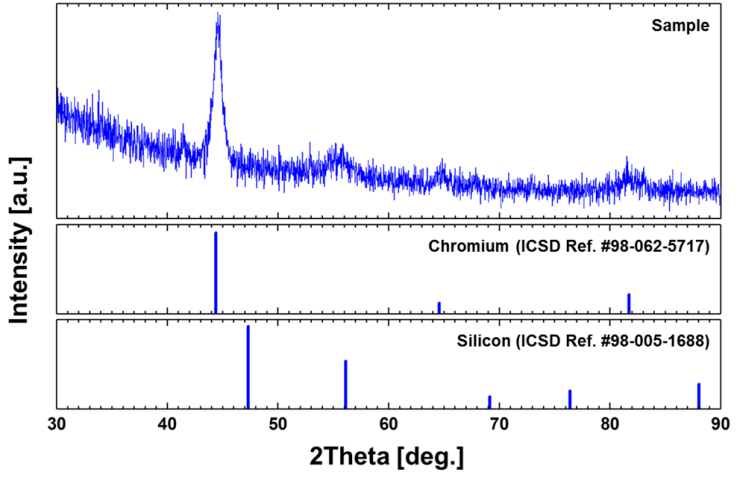

(b)

Figure 3. Sample characteristics. (a) An atomic force microscopy image of the chromium film on the micromechanical resonator. The surface roughness $\left(R_{a}\right)$ is $0.79 \mathrm{~nm} ;(\mathbf{b})$ grazing incidence X-ray diffraction (GIXRD) peaks on the chromium film on a $\mathrm{Si}(100)$ substrate. 


\subsection{Characterization Methods}

Figure 4a shows a schematic of the test apparatus for the resonant frequency measurements. Broadband ultrasonic contact transducers with different center frequencies $(1.0 \mathrm{MHz}, 2.25 \mathrm{MHz}$, $5.0 \mathrm{MHz}$, and $10.0 \mathrm{MHz}$ ) were prepared and the micromechanical resonator was placed on the transducer, to which a 5-cycle tone burst signal was transmitted using a radio frequency ultrasonic pulser. The repetition rate was adjusted to $200 \mathrm{~Hz}$ to allow sufficient time for the vibration of the micromechanical resonator to fully decay before the next signal arrived.

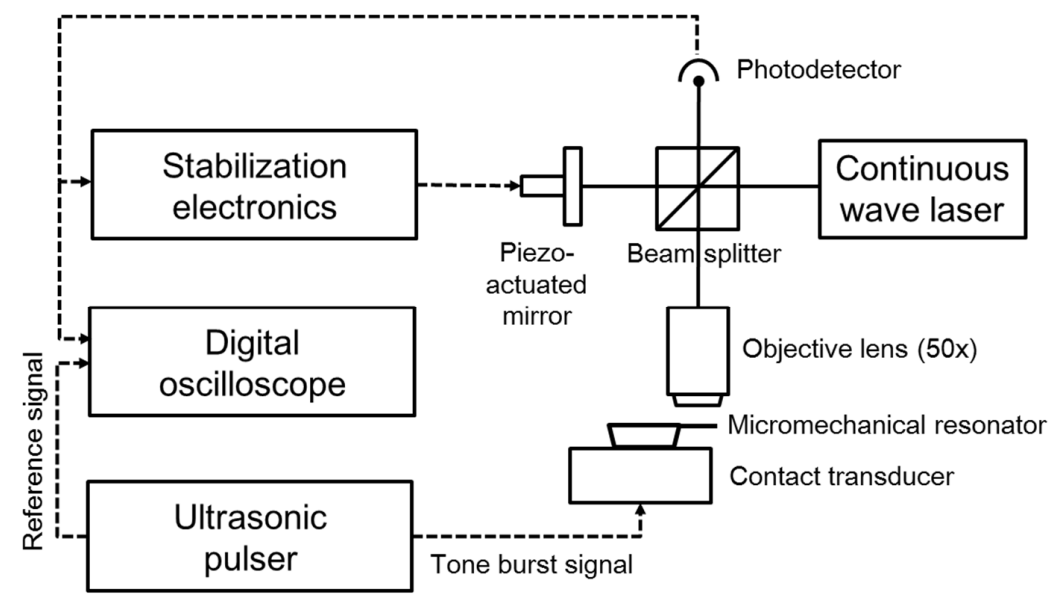

(a)

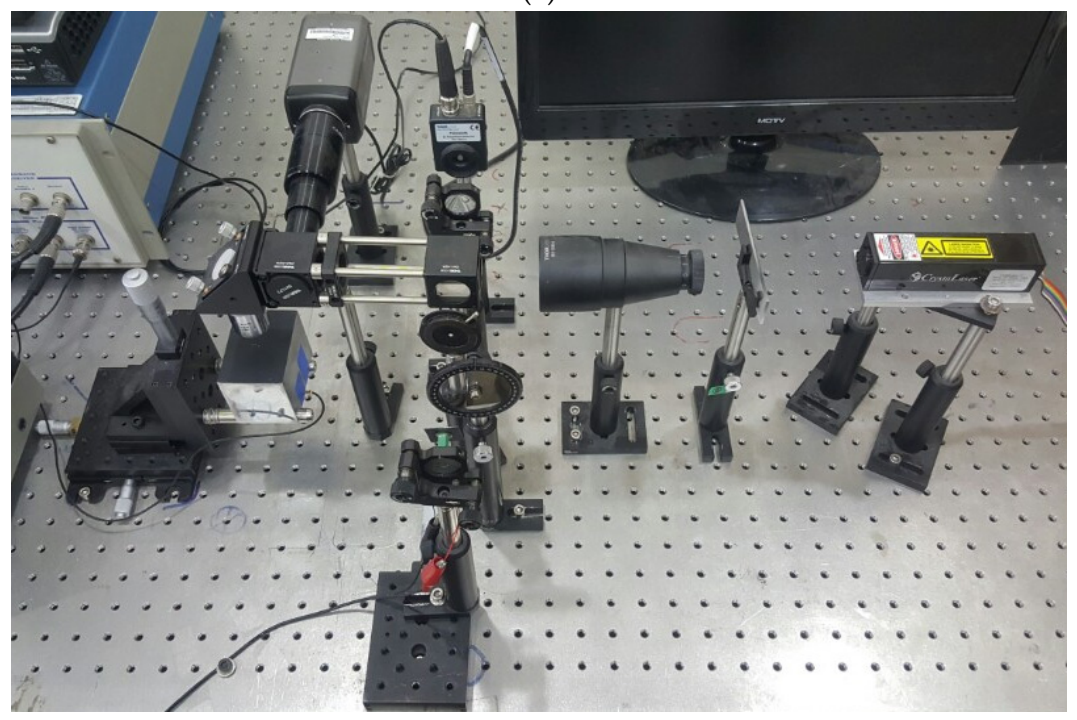

(b)

Figure 4. (a) A schematic representation of the experimental apparatus; (b) a picture of the actual interferometer setup.

The vibration was measured using a Michelson interferometer with a light source of a diode-pumped solid state laser (continuous wave at a $532 \mathrm{~nm}$ wavelength) in a single longitudinal mode. It was path-stabilized using an analog proportional-differential-integral controller and a piezo-actuated mirror to compensate the optical path length difference caused by low-frequency disturbances and noises. Intensity changes of fringe patterns were converted to voltage signals in a $50 \mathrm{MHz}$ silicon fixed gain photodetector and recorded in a $500 \mathrm{MHz}$ digital oscilloscope. The experiment was performed on an optic table with active self-leveling vibration isolation supports. Figure $4 \mathrm{~b}$ shows a picture of the actual interferometer setup. 


\section{Theory and Calculation}

The resonant frequencies obtained from the experiment and corresponding vibration modes were verified using the Euler-Bernoulli beam theory [13]. Suppose that the chromium-coated micromechanical resonator is placed in the coordinate system shown in Figure 5. Again, the length and width of the structure are $L$ and $b$, respectively.

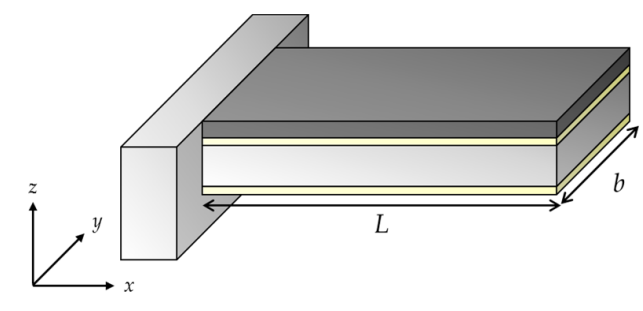

(a)

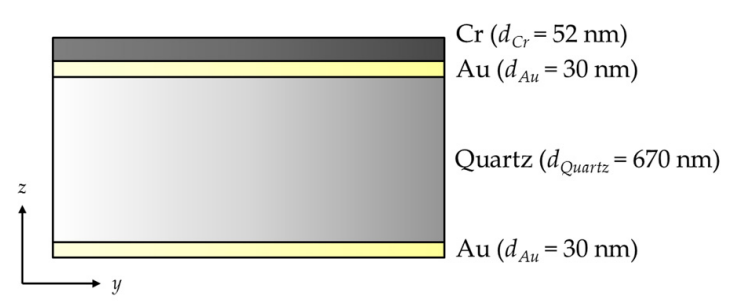

(b)

Figure 5. Dimensions of the micromechanical resonator: (a) 3D-view, $L$ is the length and $b$ is the width; (b) a cross-section, $d$ is the thickness.

The equation of motion of the beam is expressed in the form of a fourth order partial differential equation as follows:

$$
E I \frac{\partial^{4} w(x, t)}{\partial x^{4}}+\mu \frac{\partial^{2} w(x, t)}{\partial t^{2}}=0
$$

where $E$ is the Young's modulus, $I$ is the moment of inertia, $w(x, t)$ is the deflection of beam as a function of length $(x)$ and time $(t)$, and $\mu$ is the mass per unit length. The term $E I$ is also known as flexural rigidity. The resonant frequency for the $n^{\text {th }}$ vibration mode, $f_{n}$, can be obtained by solving the equation using the method of separation of variables. Suppose that the solution is expressed by the product of a spatial function, $X(x)$, and a time function, $T(t)$. Then, the deflection of beam is now written as follows:

$$
w(x, t)=X(x) T(t)
$$

Then, Equation (2) becomes:

$$
\frac{E I}{\mu} \frac{1}{X} \frac{\partial^{4} X}{\partial x^{4}}=-\frac{1}{T} \frac{\partial^{2} T}{\partial t^{2}}
$$

To satisfy Equation (4), it has to be equal to a constant, $w_{n}^{2}$, which is the square product of an angular frequency of the micromechanical resonator. Then, the left-hand side of Equation (4) is given as follows:

$$
\frac{\partial^{4} X}{\partial x^{4}}-k_{n}^{4} X=0
$$

where $k_{n}^{4}$ is expressed as:

$$
k_{n}^{4}=\frac{\omega_{n}^{2} \mu}{E I}
$$

From Equation (6), the resonant frequency of the micromechanical resonator is obtained as follows:

$$
f_{n}=\frac{1}{2 \pi} \frac{\left(k_{n} L\right)^{2}}{L^{2}} \sqrt{\frac{E I}{\mu}}
$$

where $k_{n} L$ is the coefficient associated with the vibration mode, and for a clamped-free boundary condition, $k_{1} L=1.8751, k_{2} L=4.6941$, and so on [13]. 
Since the micromechanical resonator is composed of four different layers, EI in Equation (7) is equal to the summation of the flexural rigidity of each layer:

$$
E I=E I_{A u, b o t t o m}+E I_{Q u a r t z}+E I_{A u, t o p}+E I_{C r}
$$

The moment of inertia for each layer is calculated using the parallel axis theorem as follows [14]:

$$
\begin{gathered}
I_{A u, b o t t o m}=\frac{1}{12} b d_{A u}^{3}+b d_{A u}\left(h_{n}-\frac{d_{A u}}{2}\right)^{2} \\
I_{\text {Quartz }}=\frac{1}{12} b d_{\text {Quartz }}^{3}+b d_{\text {Quartz }}\left(d_{A u}+\frac{d_{\text {Quartz }}}{2}-h_{n}\right)^{2} \\
I_{A u, t o p}=\frac{1}{12} b d_{A u}^{3}+b d_{A u}\left(1.5 d_{A u}+d_{Q u a r t z}-h_{n}\right)^{2} \\
I_{C r}=\frac{1}{12} b d_{C r}^{3}+b d_{C r}\left(2 d_{A u}+d_{\text {Quartz }}+\frac{d_{C r}}{2}-h_{n}\right)^{2}
\end{gathered}
$$

where $d$ is the film thickness. Additionally, $h_{n}$ is the neutral axis calculated as follows:

$$
\begin{aligned}
h_{n}= & {\left[E_{A u} d_{A u}^{2} / 2+E_{Q u a r t z} d_{Q u a r t z}\left(d_{A u}+d_{Q u a r t z} / 2\right)+E_{A u} d_{A u}\left(1.5 d_{A u}+d_{Q u a r t z}\right)\right.} \\
& \left.+E_{C r} d_{C r}\left(2 d_{A u}+d_{Q u a r t z}+d_{C r} / 2\right)\right] /\left[2\left(E_{A u} d_{A u}\right)+E_{Q u a r t z} d_{Q u a r t z}+E_{C r} d_{C r}\right]
\end{aligned}
$$

Lastly, $\mu$ in Equation (7) is also equal to the summation of the mass per unit length of each layer:

$$
\mu=b\left(\rho_{\text {quartz }} d_{\text {quartz }}+2 \rho_{A u} d_{A u}+\rho_{C r} d_{C r}\right)
$$

\section{Results and Discussion}

Figure 6 shows the measurement data for the 1st flexural vibration mode. The fast Fourier transform (FFT) of the time domain waveforms in Figure 6a was taken and the frequency responses are presented in Figure 6b. Resonant frequencies of $1.352 \mathrm{MHz}$ and $1.468 \mathrm{MHz}$ were obtained for the uncoated and $\mathrm{Cr}$-coated micromechanical resonators, respectively. Similarly, the waveforms for the 2nd mode were presented in Figure 7. In this case, the resonant frequencies of $8.306 \mathrm{MHz}$ and 9.093 were observed for the uncoated and $\mathrm{Cr}$-coated micromechanical resonators, respectively.

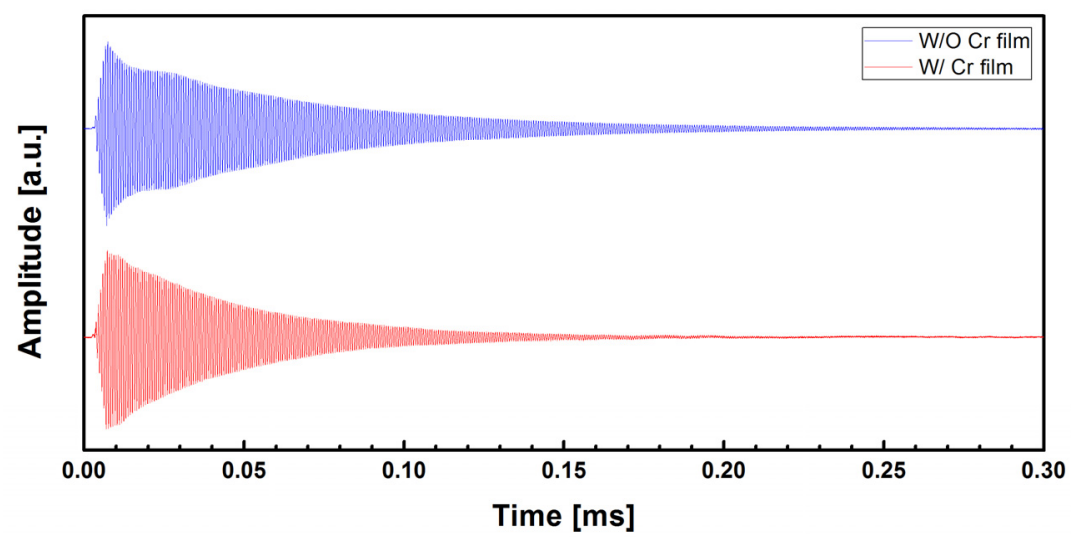

(a)

Figure 6. Cont. 


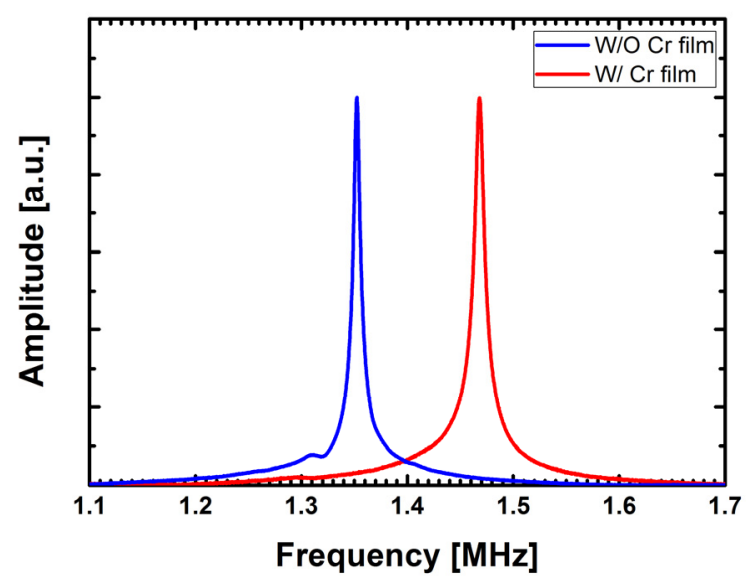

(b)

Figure 6. (a) Time-domain waveforms of the micromechanical resonators in the first flexural vibration mode; (b) frequency responses obtained from the fast Fourier transform (FFT) of the time-domain waveforms.

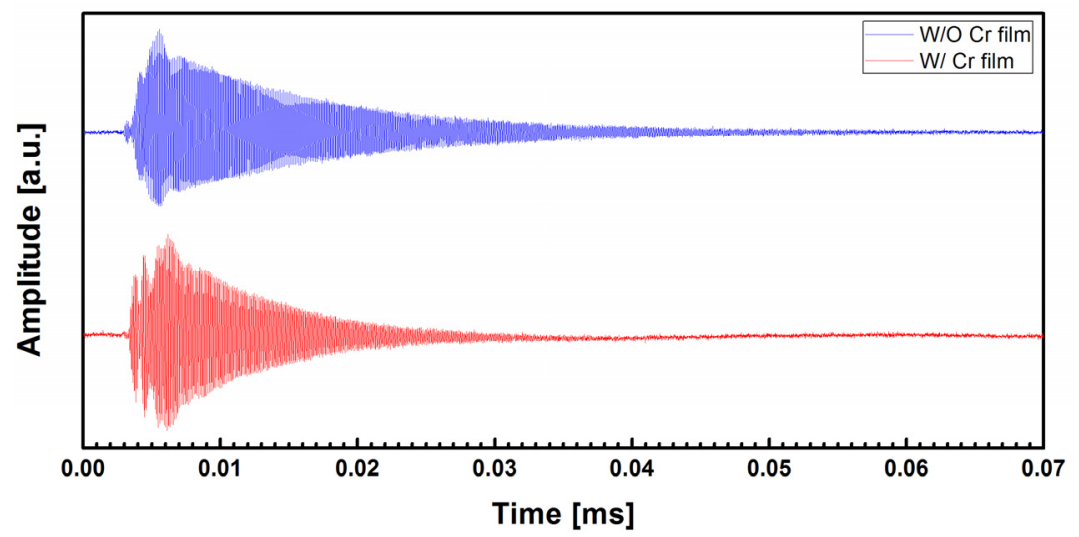

(a)

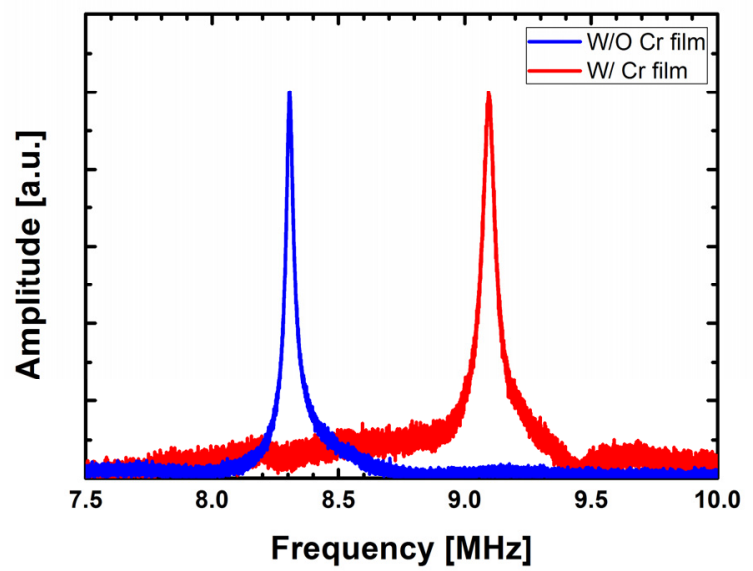

(b)

Figure 7. (a) Time-domain waveforms of the micromechanical resonators in the second flexural vibration mode; (b) frequency responses obtained from the fast Fourier transform (FFT) of the time-domain waveforms. 
Using Equation (7) with material properties introduced in Table 1, $f_{1}=1.339 \mathrm{MHz}$ and $f_{2}=8.390 \mathrm{MHz}$ were obtained for the uncoated micromechanical resonator and taking the Young's modulus of $\mathrm{Cr}$ film as a fitting parameter, $f_{1}=1.459 \mathrm{MHz}$ and $f_{2}=9.145 \mathrm{MHz}$ were obtained for $E_{C r}=139 \pm 3 \mathrm{GPa}$, considering the local fluctuation of the film thickness. Meanwhile, the bulk properties of gold were used in the analytical estimation, even though the gold film is very thin $(\sim 30 \mathrm{~nm})$. This was due to the fact that the scale effect on gold is not consistent, as summarized in Table 2. Although the elastic modulus of a gold thin-film often decreases with reduction of its thickness [15], studies show that the property is still comparable to the bulk value [16-18]. In addition, no dependency of the modulus on the film thickness was recognized in certain studies $[19,20]$. The scale effect on the gold films used in the present experiment is not yet clear, but the analytical estimations and experimental results agree excellently with each other, within $1 \%$ of the relative error as shown in Figure 8 , implying that the scale effect may not be significant in this particular sample.

Table 1. Material properties used in the analytical estimation.

\begin{tabular}{cccc}
\hline \multirow{2}{*}{ Property } & \multicolumn{3}{c}{ Material } \\
\cline { 2 - 4 } & Gold & Quartz & Chromium \\
\hline Thickness $(d)(\mathrm{nm})$ & 30 & 670 & 52 \\
Density $(\rho)\left(\mathrm{kg} / \mathrm{m}^{3}\right)$ & 19,300 & 2200 & 7190 \\
Young's modulus $(E)(\mathrm{GPa})$ & 79 & 73 & - \\
\hline
\end{tabular}

Table 2. Young's moduli of gold thin-films from literature.

\begin{tabular}{|c|c|c|c|c|}
\hline Reference & Fabrication Method & $\begin{array}{c}\text { Characterization } \\
\text { Method }\end{array}$ & $\begin{array}{c}\text { Film Thickness } \\
\text { (nm) }\end{array}$ & $\begin{array}{l}\text { Young's Modulus } \\
\text { (GPa) }\end{array}$ \\
\hline [15] & E-beam evaporation & $\begin{array}{c}\text { Nanoindentation } \\
\text { testing }\end{array}$ & $\begin{array}{l}100 \\
300 \\
500\end{array}$ & $\begin{array}{c}55.5 \\
64.1 \\
88.76\end{array}$ \\
\hline [16] & $\begin{array}{c}\text { Metal plasma immersion } \\
\text { ion implantation and } \\
\text { deposition }\end{array}$ & $\begin{array}{l}\text { Microcantilever } \\
\text { beam testing }\end{array}$ & $19-62$ & 69.1 \\
\hline \multirow[b]{2}{*}{ [17] } & \multirow[b]{2}{*}{ E-beam evaporation } & \multirow{2}{*}{$\begin{array}{l}\text { Microbeam testing } \\
\text { Nanoindentation } \\
\text { testing }\end{array}$} & \multirow[b]{2}{*}{1000} & 57 \\
\hline & & & & 74 \\
\hline [18] & $\begin{array}{c}\text { Multi-user } \\
\text { microelectromechanical } \\
\text { systems processes }\end{array}$ & $\begin{array}{l}\text { Microcantilever } \\
\text { beam testing }\end{array}$ & 500 & 78 \\
\hline \multirow{6}{*}{ [19] } & \multirow{6}{*}{ Sputtering } & \multirow{6}{*}{ Microtensile testing } & 180 & 61.0 \\
\hline & & & 310 & 49.5 \\
\hline & & & 500 & 53.9 \\
\hline & & & 680 & 53.1 \\
\hline & & & 950 & 51.2 \\
\hline & & & 1000 & 57.5 \\
\hline \multirow{3}{*}{ [20] } & \multirow{3}{*}{ E-beam evaporation } & Membrane & 300 & \multirow{3}{*}{$53-55$} \\
\hline & & deflection & 500 & \\
\hline & & experiment & 1000 & \\
\hline
\end{tabular}




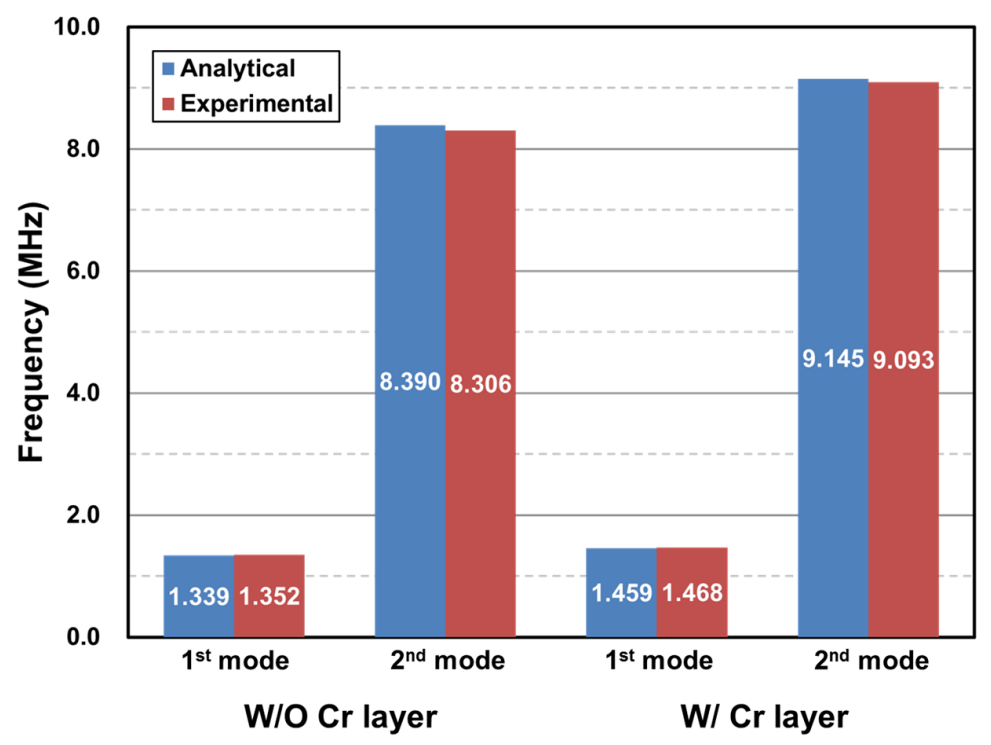

Figure 8. A comparison of resonant frequencies obtained from the experiment and the theory.

The elastic property of $\mathrm{Cr}$ in the present study is $49.8 \%$ lower than that of its bulk form, which is typically 248-279 GPa [21]. This scale effect is often observed in sub-micron Cr films and coatings for which Young's modulus varies from 43 to 185 GPa [21-23].

The quality factor $(Q)$ is an indication of damping characteristics in a resonating mechanical structure, and it is related to the performance aspects of the microresonator such as sensitivity and resolution. In general, a higher quality factor results in higher mass sensitivity, which is preferred for sensing, since the minimum detectable mass $\left(\Delta m_{\min }\right)$ is inversely proportional to $Q$ [24]:

$$
\Delta m_{\min } \propto m / Q
$$

where $m$ is the mass. The quality factor in the $n$th vibrational mode $\left(Q_{n}\right)$ is determined as follows:

$$
Q_{n}=f_{n} / \Delta f_{n}
$$

where $\Delta f_{n}$ is the full width at half maximum of the resonance peak. From Figures $6 \mathrm{~b}$ and $7 \mathrm{~b}$, the values $Q_{1, \text { uncoated }}=148.5, Q_{1, \text { Cr-coated }}=108.0, Q_{2, \text { uncoated }}=207.5$, and $Q_{2, \text { Cr-coated }}=113.6$ were obtained . These values are higher than those of a $500 \times 100 \times 1 \mu \mathrm{m}^{3}$ silicon microcantilever in air $\left(Q_{1}=19\right.$ and $\left.Q_{2}=73\right)$ [25] and comparable to those of a $225 \times 30 \times 3 \mu \mathrm{m}^{3}$ one $\left(Q_{1}=146.2\right)$ [7]. In addition, an increase of $Q$ was observed with the higher vibration mode and this is consistent with what was reported $[7,25]$.

The mass sensitivity $(S)$ is again given by [7]:

$$
S=\Delta f / \Delta m
$$

Since the Cr film has a volume of $20 \times 10 \times 0.052 \mu \mathrm{m}^{3}, S$ is calculated to be $1.6 \mathrm{~Hz} / \mathrm{fg}$ for the first mode and $10.5 \mathrm{~Hz} / \mathrm{fg}$ for the second mode. These are three orders of magnitude higher than those of conventional low-frequency silicon resonators $[7,8,26]$, and thus the present study proposes a characterization technique with high sensitivity that makes it suitable for evaluating nanoscale thin-film materials.

\section{Conclusions}

The Young's modulus of a $52 \mathrm{~nm}$ thick $\mathrm{Cr}$ film was evaluated by advanced micromechanical resonator testing. Actuation and detection of a micromechanical resonator oscillating in the high 
frequency range $(\sim 9.093 \mathrm{MHz})$ were performed using an ultrasonic tone burst signal generator and laser interferometry. The resonant frequencies for the first and second flexural vibration modes were analyzed using the Euler-Bernoulli beam theory and results showed that the measurement data are in excellent agreement with the theory, within $1 \%$ relative error. The resonant frequency shift upon deposition of the $\mathrm{Cr}$ layer revealed that the film's elastic modulus is $139 \pm 3 \mathrm{GPa}$, which is $49.8 \%$ smaller than its bulk value; this is attributable to the scale effect. This approach therefore provides an improved characterization technique for the Young's modulus of nanoscale thin-films, with high accuracy and sensitivity up to $10.5 \mathrm{~Hz} / \mathrm{fg}$.

Acknowledgments: This research was supported by Basic Science Research Program through the National Research Foundation of Korea (NRF) funded by the Ministry of Science, ICT \& Future Planning (No. 2015R1C1A1A01053635).

Conflicts of Interest: The author declares no conflict of interest.

\section{References}

1. Chang, K.-B.; Kim, Y.Y.; Sue, J.; Lee, H.; Chung, W.-Y.; Lee, K.-H.; Park, Y.-K.; Jung, E.; Chung, I. The novel stress simulation method for contemporary dram capacitor arrays. In Proceedings of the 2013 International Conference on Simulation of Semiconductor Processes and Devices (SISPAD), Glasgow, UK, 3-5 September 2013; IEEE: New York, NY, USA, 2013; pp. 424-427.

2. Bamber, M.; Cooke, K.; Mann, A.; Derby, B. Accurate determination of Young's modulus and Poisson's ratio of thin films by a combination of acoustic microscopy and nanoindentation. Thin Solid Films 2001, 398, 299-305. [CrossRef]

3. Pharr, G.M. Recent advances in small-scale mechanical property measurement by nanoindentation. Curr. Opin. Solid State Mater. Sci. 2015, 19, 315-316. [CrossRef]

4. Kihara, Y.; Nagoshi, T.; Chang, T.-F.M.; Hosoda, H.; Tatsuo, S.; Sone, M. Tensile behavior of micro-sized specimen made of single crystalline nickel. Mater. Lett. 2015, 153, 36-39. [CrossRef]

5. Zhang, F.; Krishnaswamy, S.; Fei, D.; Rebinsky, D.A.; Feng, B. Ultrasonic characterization of mechanical properties of Cr-and W-doped diamond-like carbon hard coatings. Thin Solid Films 2006, 503, 250-258. [CrossRef]

6. Mahmoud, M.A. Validity and accuracy of resonance shift prediction formulas for microcantilevers: A review and comparative study. Crit. Rev. Solid State Mater. Sci. 2016, 41, 386-429. [CrossRef]

7. Lakshmoji, K.; Prabakar, K.; Kumar, A.; Brijitta, J.; Jayapandian, J.; Tata, B.V.R.; Tyagi, A.K.; Sundar, C.S. Microcantilever-based mass sensors: Working at higher modes against reducing the dimensions. Micro Nano Lett. 2012, 7, 613-616. [CrossRef]

8. Narducci, M.; Figueras, E.; Lopez, M.J.; Gracia, I.; Santander, J.; Ivanov, P.; Fonseca, L.; Cane, C. Sensitivity improvement of a microcantilever based mass sensor. Microelectron. Eng. 2009, 86, 1187-1189. [CrossRef]

9. Brown, K.A.; Yang, B.H.; Westervelt, R.M. Self-driving capacitive cantilevers for high-frequency atomic force microscopy. Appl. Phys. Lett. 2012, 100, 053110. [CrossRef]

10. Chaste, J.; Eichler, A.; Moser, J.; Ceballos, G.; Rurali, R.; Bachtold, A. A nanomechanical mass sensor with yoctogram resolution. Nat. Nanotechnol. 2012, 7, 300-303. [CrossRef] [PubMed]

11. Li, M.; Tang, H.X.; Roukes, M.L. Ultra-sensitive NEMS-based cantilevers for sensing, scanned probe and very high-frequency applications. Nat. Nanotechnol. 2007, 2, 114-120. [CrossRef] [PubMed]

12. Burke, B.G.; LaVan, D.A. Characterization of a 10-MHz quadrant APD for measuring frequency oscillations and tip displacements of microcantilevers. Appl. Phys. B Lasers Opt. 2012, 109, 127-132. [CrossRef]

13. Landau, L.D.; Kosevich, A.; Pitaevskii, L.P.; Lifshitz, E.M. Theory of Elasticity; Pergamon Press: Oxford, UK, 1986.

14. Cortes, F.; Sarria, I. Dynamic analysis of three-layer sandwich beams with thick viscoelastic damping core for finite element applications. Shock Vib. 2015, 2015. [CrossRef]

15. Birleanu, C.; Pustan, M. The Effect of Film Thickness on the Tribomechanical Properties of the Chrome-Gold Thin Film. In Proceedings of the 2016 Symposium on Design, Test, Integration and Packaging of MEMS/MOEMS (DTIP), Budapest, Hungary, 30 May-2 June 2016; IEEE: New York, NY, USA, 2016; pp. 1-6. 
16. Salvadori, M.C.; Brown, I.G.; Vaz, A.R.; Melo, L.L.; Cattani, M. Measurement of the elastic modulus of nanostructured gold and platinum thin films. Phys. Rev. B 2003, 67. [CrossRef]

17. Nix, W.D. Mechanical properties of thin films. Metall. Mater. Trans. A 1989, 20, 2217-2245. [CrossRef]

18. Pamula, V.K.; Jog, A.; Fair, R.B. Mechanical Property Measurement of Thin-Film Gold Using Thermally Actuated Bimetallic Cantilever Beams. In Proceedings of the Modeling and Simulation of Microsystems, Hilton Head Island, SC, USA, 19-21 March 2001.

19. Huh, Y.-H.; Kim, D.-I.; Kim, D.-J.; Lee, H.-M.; Park, J.-H. Dependency of micro-mechanical properties of gold thin films on grain size. In Engineering Against Fracture; Springer: Berlin, German, 2009; pp. 339-346.

20. Espinosa, H.D.; Prorok, B.C. Size effects on the mechanical behavior of gold thin films. J. Mater. Sci. 2003, 38, 4125-4128. [CrossRef]

21. Nilsson, S.G.; Borrise, X.; Montelius, L. Size effect on Young's modulus of thin chromium cantilevers. Appl. Phys. Lett. 2004, 85, 3555-3557. [CrossRef]

22. Rehder, G.P.; Carreño, M.N. Piezoelectric stimulation of microcantilever beams for Young's modulus determination of Amorphous Hydrogenated Silicon Carbide. ECS Trans. 2008, 14, 63-71.

23. Schneider, D.; Tucker, M.D. Non-destructive characterization and evaluation of thin films by laser-induced ultrasonic surface waves. Thin Solid Films 1996, 290, 305-311. [CrossRef]

24. Waggoner, P.S.; Craighead, H.G. Micro-and nanomechanical sensors for environmental, chemical, and biological detection. Lab Chip 2007, 7, 1238-1255. [CrossRef] [PubMed]

25. Ghatkesar, M.K.; Barwich, V.; Braun, T.; Ramseyer, J.-P.; Gerber, C.; Hegner, M.; Lang, H.P.; Drechsler, U.; Despont, M. Higher modes of vibration increase mass sensitivity in nanomechanical microcantilevers. Nanotechnology 2007, 18, 445502. [CrossRef]

26. Chaudhary, M.; Gupta, A. Microcantilever-based Sensors. Def. Sci. J. 2009, 59, 634-641. [CrossRef]

(C) 2017 by the author. Licensee MDPI, Basel, Switzerland. This article is an open access article distributed under the terms and conditions of the Creative Commons Attribution (CC BY) license (http:/ / creativecommons.org/licenses/by/4.0/). 